\title{
Chronic intra-diploic hematoma associated with anti-platelet aggregating medicine - a rare clinical
}

\section{case report}

\begin{abstract}
A 78 year old gentleman on anti-platelet (Clopidogrel) therapy presented with uni-ocular visual impairment and ipsilateral non-pulsatile progressive proptosis. MRI (magnetic resonance imaging) brain showed an intra-Diploic expansile lytic lesion which had homogenous hyper intensity on T1 weighted images and heterogeneous intensity on T2 weighted images. Histopathology was suggestive of an organizing hematoma. Intra-Diploic hematoma, though mimicking Aneurysmal bone cyst is a different clinico-pathological entity. The etiology and pathogenesis of this rare clinical entity is discussed.
\end{abstract}

Keywords: Intradiploic, Chronic hematoma, Calvarial cystic lesion, Clopidogrel, Antiplatelet therapy, Aneurysmal bone cyst
Volume I Issue I - 2014

\section{Syed Ali S, Hariprakash Chakravarthy, Balamurugan Mangaleshwaran}

Department of Neurosurgery, Apollo Specialty Hospital, India

Correspondence: Syed Ali S, Department of Neurosurgery, Apollo Specialty Hospital, Apollo Hospitals, 320, Anna Salai, Nandanam, Rathna Nagar,Alwarpet, Chennai, Tamil Nadu 600035, India,Tel +91-9094663366, Email dr.syed@live.com

Received: April 24, 2014 | Published: May 15, 2014

\section{Introduction}

Chronic Intra-Diploic hematoma is a rare clinical entity, with eight cases having been reported in the literature. It presents as an expansive intra-Diploic lytic lesion mimicking Aneurysmal bone cyst. It occurs most often in young individuals in relation to previous cranial trauma or coagulation abnormality. We are reporting a 78years old male on long term anti-platelet therapy, who presented with a chronic intradiplopic hematoma.

\section{Case report}

A 78years old male presented with a history of progressive impairment of vision in the right eye for the last 2years. Visual deterioration had been gradually progressive more so in the last 6 months. Protrusion of right eye ball had also been noticed during the last 3months. There was no history of diplopia or symptoms suggestive of visual field defects or symptoms suggestive of raised intracranial pressure, other cranial nerve dysfunction or impairment of Spino-motor system. There was history of having been on regular oral medications for diabetes mellitus for 20years and hypertension for 5years. He has been on anti-platelet (Clopidogrel) medicine since
5 years as a cardiac prophylaxis. Repeated enquiries revealed that there had been a few minor head trauma due to falls in the past four to five years.

On general examination, there was proptosis of $26 \mathrm{~mm}$ of the right eye with downward and medial displacement of the eyeball. The visual acuity on the right eye was 'counting fingers' from 1 foot distance and on left eye it was $6 / 12$. There was no visual field defect in the left eye. Pupils were $4 \mathrm{~mm}$ bilaterally, with relative afferent pupillary defect (RAPD) on the right eye. Fundi examination showed no abnormality. There was restriction of movement in the right eye on attempted elevation and abduction. There was no cataract on both eyes. Rest of the cranial nerves and Spino-motor system examination were normal. There was a diffuse bulge in the right temple which was tender and firm.

MRI brain showed a right spheno-temporal Diploic, expansile abnormal area measuring $7 \mathrm{~cm} \times 5 \mathrm{~cm} \times 3 \mathrm{~cm}$. It was homogenously hyper intense on $\mathrm{T} 1$ weighted images and showed heterogeneous intensities on T2 weighted images with hypo intense capsule and hyper intense cystic center (Figure 1). Erosion of both the outer and inner table was evident and there was extension to the right orbit.

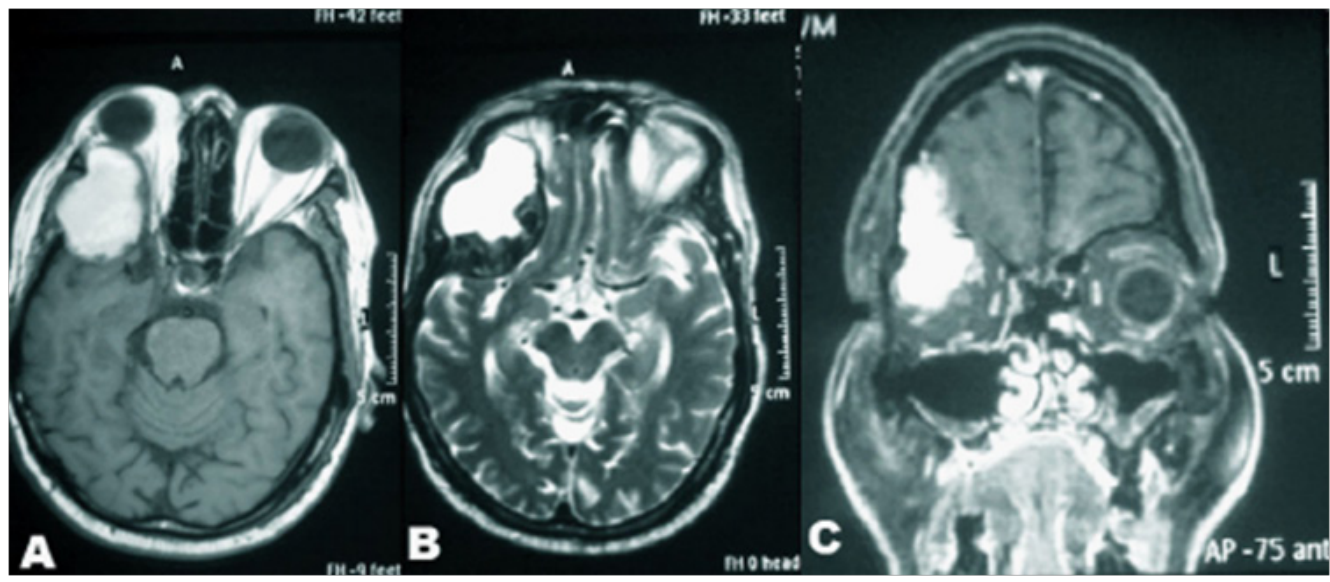

Figure I MRI images (A) TIWI axial image showing a hyperintense lesion in the diploic space of the right spheno-temporal bone with erosion of the orbital roof. (B) T2WI axial image showing hetero-intense lesion with peripheral hypo-intense cystic center. (C) TIWI coronal image with contrast showing nonenhancing lesion with orbital involvement. 
Surgical excision of the lesion was planned to primarily relieve the pressure effect and obtain histopathological diagnosis. A right front-temporal scalp flap and temporalis muscle flap were elevated separately to expose the bony lesion. Lesion was seen eroding the outer table partially and inner table completely. (Figure 2, 2a-Operative photograph) Thick fleshy pinkish white capsule could be visualized at the eroded regions of the bone. As the capsule was opened, a dirty brown (mud) colored mucky material was visualized. The lesion was extending along the roof and lateral orbital wall. The diplopic space was cleared out by scooping the material and removing the capsule. The eroded bone was removed. The bony defect was left open without primary cranioplasty as infectious etiology could not be ruled out during surgery. Bacterial culture and fungal smear was negative. Histopathology of the tissue along with the capsule revealed hemorrhagic material with focal collections of histiocytes and cholesterol clefts, with hemosiderinophages, foreign body giant cells and dystrophic calcifications suggestive of organizing hematoma (Figure 3).

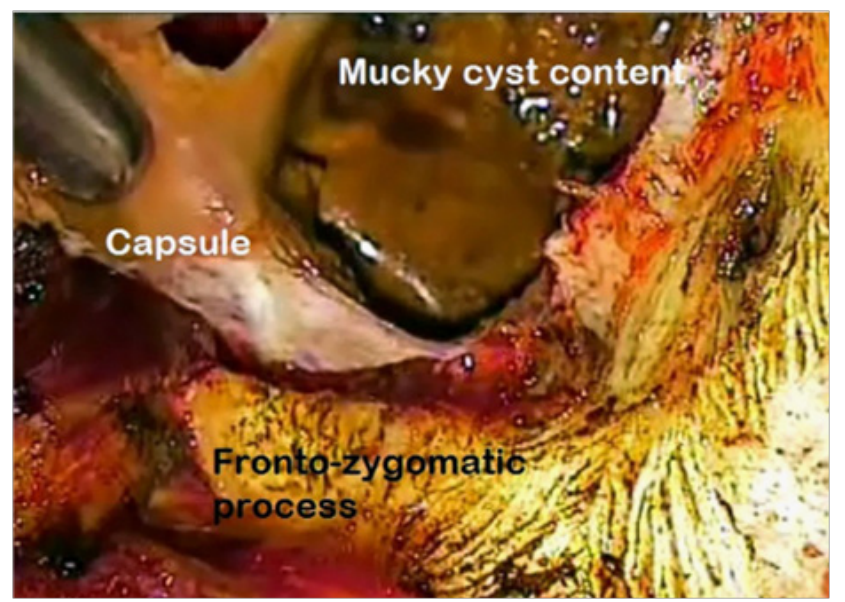

Figure 2 H\&E image of the hematoma showing cholesterol clefts (A), foreign body giant cells (B), clumps of red blood corpuscles (C), and histiocytes (D).

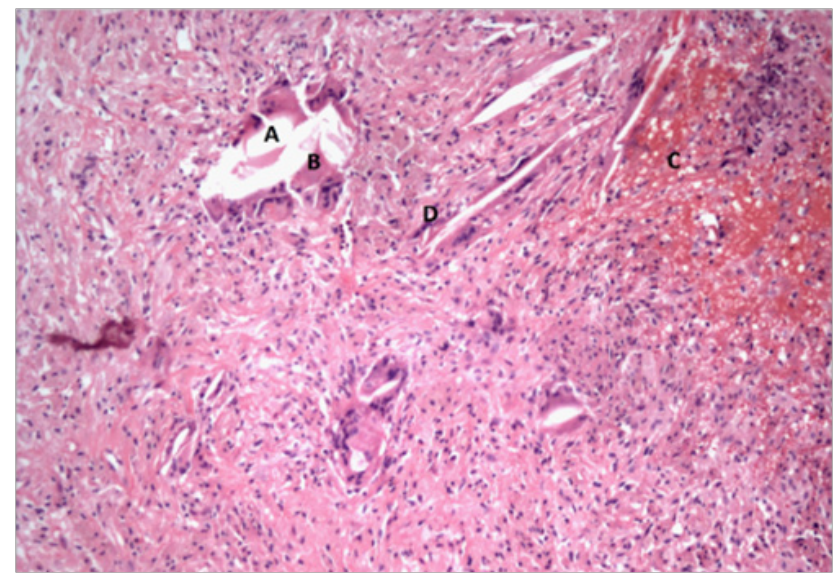

Figure 3 Per-operative picture showing fleshy capsule with mucky brownish cyst content.

Postoperatively his range of right eye movements improved and proptosis resolved. There was no improvement in the vision. On the 3rd month follow up, there is no recurrence of symptoms.

Post operative imaging showed no recurrence of the lesion and craniotomy defect.

\section{Discussion}

Intra Diploic chronic hematoma is a rare condition. The first case was reported in 1934. There have been only eight other reported cases till date. The etiology and pathogenesis still remains uncertain. The previously reported cases, had association with prior trauma or coagulation abnormality. ${ }^{1,2}$ Secondary Intradiploic hematomas have been reported with underlying Intradiploic epidermis and Aneurysmal bone cyst. ${ }^{3,4}$ Vascular malformations like Intradiploic hemangioma and Diploic venous fistula have been reported to lead to Intradiploic hematoma. ${ }^{5,6}$ It is most often reported in young adults but can present at any age, in the reported cases age has ranged from 2 years to 58 years. ${ }^{7,8}$ Expansion of the diplopic space leads to mass effect and involvement of medial sphenoid wing leads to proptosis and visual impairment. The expansion and growth of the lesion has been postulated to be similar to that of Aneurysmal bone cyst. ${ }^{2}$ Insignificant prior trauma usually initiates the process of an Intradiploic bleed ${ }^{9}$. Healing process leads to organization of the clot, but in presence of anomalous clot formation due to coagulation abnormality or platelet dysfunction, small recurrent hemorrhages occurs, causing expansion of the clot. ${ }^{10}$

Chronic diplopic hematoma is differentiated from an Aneurysmal bone cyst by the absence of trabecular endothelium lined sinusoidal blood filled spaces and multinucleated giant macrophages. ${ }^{10,11}$ The CT (computerized tomography) and MRI features are similar to that of Aneurysmal bone cyst with lytic expansile Intradiploic lesion, with heterogeneous T1 hyper intensity, suggestive of cholesterol crystals and blood degradation products..$^{10,12}$ Surgical excision is the treatment of choice and recurrence has not been reported in the literature.

\section{Conclusion}

Intradiploic hematoma is a rare clinical entity, often associated with prior history of trauma or in association with coagulation abnormality. This report showcases the eldest individual so far reported in the literature, to have had chronic intra-Diploic hematoma, which could possibly be related to long term anti-platelet (Clopidogrel) therapy and multiple trivial minor traumas.

\section{Acknowledgments}

None.

\section{Conflicts of interest}

The authors of the manuscript of reference state that there is no conflict of interest related to the article.

\section{References}

1. Dange N, Mahore A, Avinash KM, et al. Chronic intradiploic hematoma in patients coagulopathy. J Clin Neurosci. 2010;17(8):1047-1049.

2. Mobbs RJ, Gollapudi PR, Fuller JW, et al. Intradiploic hematoma after skull fracture: case report and literature review. Surg Neurol. 2000;54(1):87-91.

3. Aiyama H, Utsunomiya A, Suzuki S, et al. Case of enlargement of an intradiploic epidermoid cyst by a head contusion. Brain Nerve. 2009;61(6):707-710.

4. Sanghvi DA, Iyer VR, Chagla AS, et al. Intradiploic frontal bone aneurysmal bone cyst in a child: a case report. Dentomaxillofac Radiol. 2010;39(4):252-255. 
5. Gottfried ON, Gluf WM, Schmidt MH. Cavernous hemangioma of the skull presenting with subdural hematoma. Case report. Neurosurg Focus. 2004;17(4):ECP1.

6. Gonzalez-Tortosa J, de San Pedro JR, Parrilla G, et al. Chronic spontaneous diploic hematoma. J Neurosurg. 2011;114(6):1812-1817.

7. Goel AK, Desai K, Pati S. Unusual intradiploic hematoma. J Neurosurg. 2000;93(5): 895-896.

8. Giammusso V, Strukelj S. Intradiploic hematoma in a patient who underwent internal drainage of CSF for hydrocephalus. J Neurosurg Sci. 1980;24(2):105-108
9. Nagi S, Megdiche H, Daoud H, et al. Intradiploic hematoma: report of two cases and review of literature. Tunis Med. 2005;83(7):426-428.

10. Dabska M, Buraczewski J. Aneurysmal bone cyst. Pathology, clinical course and radiologic appearances. Cancer. 1969;23(2):371-389.

11. Mankin HJ, Hornicek FJ, Ortiz-Cruz E, et al. Aneurysmal bone cyst: a review of 150 patients. J Clin Oncol. 2005; 23(27):6756-6762.

12. Griffin C, DeLaPaz R, Enzmann D. MR and CT correlation of cholesterol cysts of the petrous bone. AJNR Am J Neuroradiol. 1985;8(5):825-829. 